BMJ Open

Diabetes

Research

\& Care

\title{
Sex differences over time for glycemic control, pump use and insulin dose in patients aged 10-40 years with type 1 diabetes: a diabetes registry study
}

\author{
Claudia Boettcher (D) , ${ }^{1}$ Sascha R Tittel, ${ }^{2,3}$ Thomas Meissner, ${ }^{4}$ Bettina Gohlke, ${ }^{5}$ \\ Rainer Stachow, ${ }^{6}$ Axel Dost, ${ }^{7}$ Sybille Wunderlich, ${ }^{8}$ Iris Lowak, ${ }^{9}$ Stefanie Lanzinger ${ }^{2,3}$
}

To cite: Boettcher $\mathrm{C}$, Tittel SR, Meissner T, et al. Sex differences over time for glycemic control, pump use and insulin dose in patients aged 10-40 years with type 1 diabetes: a diabetes registry study. BMJ Open Diab Res Care 2021;9:e002494. doi:10.1136/ bmjdrc-2021-002494

- Additional supplemental material is published online only. To view, please visit the journal online (http://dx.doi. org/10.1136/bmjdrc-2021002494).

Received 22 July 2021 Accepted 23 November 2021

Check for updates

\section{(c) Author(s) (or their} employer(s)) 2021. Re-use permitted under CC BY-NC. No commercial re-use. See rights and permissions. Published by BMJ.

For numbered affiliations see end of article.

Correspondence to Dr Claudia Boettcher; claudia.boettcher@insel.ch

\section{ABSTRACT}

Introduction To evaluate sex differences in people with type 1 diabetes concerning changes in glycemic control and trends in insulin pump use and insulin dose over two decades in adolescents and one-and-a-half decades in adults.

Research design and methods People aged 10-20 years (data years 1999-2018) and 21-40 years (data years 2004-2018) with type 1 diabetes were identified in the Diabetes Prospective Follow-up Registry (DPV). All available patients' data sets of the respective period were used for linear regression analyses to investigate trends in HbA1c, pump use, insulin doses and body mass index SD scores (BMI-SDS) in females and males. In addition, stratification by migrant background was made for the adolescent group.

Results In the youth group ( $\mathrm{n}=68 \mathrm{662}$ ), both boys and girls showed an $\mathrm{HbA1C}$ decrease over the period examined. After stratification for migrant background, an $\mathrm{HbA} 1 \mathrm{C}$ convergence between boys and girls was seen in those without migrant background as of 2016. Usage of insulin pumps increased continuously from $3 \%$ (boys and girls) to $47 \%$ (boys) and $54 \%$ (girls), respectively. The daily insulin dose in units per kilogram body weight and day increased continuously from 1999 to 2018. An insulin dose leveling between boys and girls occurred. BMI-SDS consistently increased in girls whereas only slight variations were observed in boys.

The adult group ( $\mathrm{n}=15380$ ) showed constant HbA1c sex differences from 2004 to 2018 with lower HbA1c level in females. The use of insulin pump therapy rose from $18 \%$ to $35 \%$ (males) and $30 \%$ to $50 \%$ (females).

Conclusions The gap in metabolic control between boys and girls with type 1 diabetes seems to close, but predominantly in adolescents without a migrant background. Improved HbA1c was associated with increased insulin pump use, especially in girls. In adult patients, sex differences in metabolic control and insulin pump use persist: women show constantly lower HbA1c values and higher insulin pump use.

\section{INTRODUCTION}

Over the last decades, sex and gender differences in medicine came into the focus of interest. Growing evidence suggests that

\section{Significance of this study}

What is already known about this subject?

- Sex and gender differences exist regarding diabetes mellitus.

What are the new findings?

- Pre-existing HbA1c sex differences seem to clear in type 1 children and adolescents without migrant background.

- There is a time lag concerning HbA1c sex differences in adolescents with migrant background.

- HbA1c values declined among all youth groups from 2016 to 2018 onwards.

- Adults' sex differences for HbA1C and insulin pump use persist.

How might these results change the focus of research or clinical practice?

- Efforts are necessary to equalize gaps regarding sex and gender and to support vulnerable groups with type 1 diabetes.

sex and gender affect the pathophysiology, incidence, prevalence, symptoms and signs, course and response to therapy of many diseases, including diabetes mellitus. ${ }^{1}$ For type 1 diabetes, for example, it is known that women have higher excess all-cause mortality than men. ${ }^{2}$ In addition, a migrant background might aggravate sex and gender differences, as minority status itself is associated with a more unsatisfactory health outcome in youth with type 1 diabetes. ${ }^{3}$ With this knowledge in mind, the new medical science gender medicine was-or is in the process of beingimplemented into medical education institutions and networks. ${ }^{4-8}$ The growing awareness about sex and gender differences accompanies an enormous encompassing change in diabetes therapy, due to new diabetes drugs and mainly due to technical innovation like sophisticated insulin pumps. ${ }^{9}$ 
The best possible metabolic control to avoid acute and long-term sequelae is the declared aim in diabetes therapy-for all sexes, males and females alike. The still most frequently used indicator for glycemic control is $\mathrm{HbAlc}$, with an international guidelines' target of nowadays' $<53 \mathrm{mmol} / \mathrm{mol}(<7 \%)$ for children, adolescents and adults. ${ }^{11}{ }^{11}$ Furthermore, diabetes registries for all age groups-national, international or regional-started documenting the progress in glycemic control and other clinical variables systematically since the late 1990s (see ref 12), giving an excellent opportunity to investigate changes over time.

The present study aimed to evaluate sex differences and their changes over the last decades in two generations of individuals with type 1 diabetes against the backdrop of altering gender awareness. Glycemic control, insulin pump use, insulin dose and body mass index SD scores (BMI-SDS) were part of the investigation in a large international diabetes registry cohort.

\section{RESEARCH DESIGN AND METHODS}

As the basis for this study served the international multicenter, Diabetes Prospective Follow-up Registry (DPV). Currently, 495 pediatric and adult specialized diabetes centers from Germany $(n=445)$, Austria $(n=45)$, Switzerland $(n=4)$ and Luxemburg $(n=1)$ prospectively document demographic and clinical data of individuals with any diabetes, resulting in data of more than 560000 patients (September 2019). For central analysis and quality assurance, participating DPV centers transfer locally collected and pseudonymized data twice a year to Ulm University, Ulm, Germany. In case of inconsistency or implausibility, data are reported back to the centers for verification or correction. The local/national review boards have approved the data collection of each participating center.

We searched the DPV database according to the following criteria: patients with type 1 diabetes (as documented in the registry's master data), aged 10-40 years, period 1999-2018 (for patients 10-20 years of age) or 2004-2018 (for patients $>20-40$ years of age) and documented HbA1c and type of diabetes therapy. The search resulted in a study sample of 84042 patients originating from 489 centers. Demographic variables of our study group included age, patients' duration of diabetes, age at diabetes onset, sex and migrant background (defined as at least one parent and the patient born in another country than the participating four nations, or the patient alone born in another country than the participating four nations). We categorized the population into two age groups: 10-20 (youth group) and $>20-40$ (adult group) years of age. Further age grouping $(10-15,>15-20,>20-30$ and $>30-40$ years of age) was done for confounder adjustment. Individuals' duration of diabetes was grouped into $\leq />5$ years. The use of insulin pumps was registered. Clinical data were HbAlc (mathematically standardized to the Diabetes Control and Complications Trial reference range $(21-43 \mathrm{mmol} /$ $\mathrm{mol} / 4.05 \%-6.05 \%)),{ }^{13}$ insulin dose in units per kilogram body weight and day and BMI-SDS based on the cohort of Arbeitsgemeinschaft Adipositas im Kindes- und Jugendalter. ${ }^{14}$ For each patient, all available variables were aggregated per calendar year as a median, resulting in maximally 20 data sets per patient in the youth group (due to the time frame) and maximally 15 data sets in the adult group (also limited by the chosen period 20042018). Patients may have contributed data to the analysis in both age groups for a maximum of 20 years.

We calculated linear and logistic regression models (SAS PROC GLIMMIX) adjusted for repeated measurements and a simple autoregressive covariance structure to evaluate trends over time for $\mathrm{HbAlc}$, insulin pump use, insulin dose and BMI-SDS. The autoregressive covariance structure considers that chronologically close measurement points correlate more closely than measurement points wide apart. Df were calculated using the between-within method. Year of treatment, sex, age group, diabetes duration group and an interaction term of year of treatment with sex were modeled as fixed effects. In a second step, we stratified the youth group by migrant background. We use the least square means for the interaction of year of treatment with sex to present results graphically. In a sensitivity analysis (SA) to test the model's robustness, we included only patients with at least two documented treatment years (online supplemental material).

A $p$ value $<0.05$ indicated statistical significance. All statistical analyses were performed with SAS for Windows V.9.4 software (SAS Institute).

\section{RESULTS}

\section{Description of the study cohort}

Of the 564734 individuals documented in DPV as 2019, 84042 fulfilled the inclusion criteria. Of these, 68662 were defined as the youth group and 15380 as the adult group.

The baseline median age of the youth group included in this study was 12.0 (SA 11.6) years, baseline median diabetes duration 1.9 (SA 1.8) years, and baseline median HbAlc $7.73 \%$ (60.95 $\mathrm{mmol} / \mathrm{mol}$ ) (SA $7.67 \%$ $(60.31 \mathrm{mmol} / \mathrm{mol}))$. The adult group had a median age of 30.6 (SA 30.0 (IQR 25.3-34.7)) years, median diabetes duration of 8.6 (SA 9.2) years, and a median HbAlc value of $64.57 \mathrm{mmol} / \mathrm{mol}(8.06 \%)(\mathrm{SA} 60.39 \mathrm{mmol} / \mathrm{mol}$ $(7.68 \%))$. Table 1 shows the population's characteristics in detail aggregated for the first available year per patient.

\section{HbA1c trends}

The linear regression model with adjustment for age, diabetes duration, migration and repeated measurements showed an overall decrease in the youth group for HbA1c: for boys from 65.62 (65.06-66.18) $\mathrm{mmol} / \mathrm{mol}$ $(8.15(8.10-8.21) \%)$ (least square mean $(95 \% \mathrm{CI}))$ in the year 1999 to $64.03(63.70-64.35) \mathrm{mmol} / \mathrm{mol}(8.00$ 
Table 1 Characteristics of the study population, classified into youth and adult groups

\begin{tabular}{|c|c|c|c|c|c|c|c|c|}
\hline Parameter & Youth group & $\mathbf{n}$ & Youth group SA & $\mathbf{n}$ & Adult group & $\mathbf{n}$ & Adult group SA & $\mathbf{n}$ \\
\hline $\begin{array}{l}\text { First year of } \\
\text { analysis }\end{array}$ & $\begin{array}{l}2009 \\
(2004-2014)\end{array}$ & 68662 & $\begin{array}{l}2009 \\
(2003-2013)\end{array}$ & 56620 & $\begin{array}{l}2011 \\
(2007-2015)\end{array}$ & 15380 & $\begin{array}{l}2010 \\
(2006-2014)\end{array}$ & 6672 \\
\hline Age (years) & $\begin{array}{l}12.0 \\
(10.4-14.6)\end{array}$ & 68662 & $\begin{array}{l}11.6 \\
(10.4-14.1)\end{array}$ & 56620 & $\begin{array}{l}30.6 \\
(25.6-35.45)\end{array}$ & 15380 & $\begin{array}{l}30.0 \\
(25.3-34.7)\end{array}$ & 6672 \\
\hline $\begin{array}{l}\text { Female/male } \\
\text { sex }(\%)\end{array}$ & $46.8 / 53.2$ & 68662 & $46.9 / 53.1$ & 56620 & $49.5 / 51.5$ & 15380 & $51.0 / 49.0$ & 6672 \\
\hline $\begin{array}{l}\text { Migration } \\
\text { background (\%) }\end{array}$ & 17.0 & 68662 & 17.1 & 68662 & 2.1 & 15380 & 1.5 & 6672 \\
\hline $\begin{array}{l}\text { Diabetes } \\
\text { duration (years) }\end{array}$ & $\begin{array}{l}1.9 \\
(0.2-5.6)\end{array}$ & 68662 & $\begin{array}{l}1.8 \\
(0.2-5.4)\end{array}$ & 56620 & $\begin{array}{l}8.6 \\
(0.6-17.3)\end{array}$ & 15380 & $\begin{array}{l}9.2 \\
(1.2-17.51)\end{array}$ & 6672 \\
\hline $\begin{array}{l}\text { Insulin pump } \\
\text { use (\%) }\end{array}$ & 19.5 & 65498 & 18.7 & 54177 & 26,6 & 11974 & 31.8 & 4569 \\
\hline $\mathrm{HbA1c}(\%)$ & $\begin{array}{l}7.73 \\
(6.87-9.02)\end{array}$ & 67095 & $\begin{array}{l}7.67 \\
(6.83-8.84)\end{array}$ & 55534 & $\begin{array}{l}8.06 \\
(6.89-9.91)\end{array}$ & 14831 & $\begin{array}{l}7.68 \\
(6.72-9.11)\end{array}$ & 6478 \\
\hline $\begin{array}{l}\mathrm{HbA1c}(\mathrm{mmol} / \\
\mathrm{mol})\end{array}$ & $\begin{array}{l}60.95 \\
(51.56-75.06)\end{array}$ & 67095 & $\begin{array}{l}60.31 \\
(51.11-73.09)\end{array}$ & 55534 & $\begin{array}{l}64.57 \\
(51.81-84.80)\end{array}$ & 14831 & 60.39 (49.93-76.06) & 6478 \\
\hline $\begin{array}{l}\text { Insulin dose (IU/ } \\
\text { kg/day) }\end{array}$ & $\begin{array}{l}0.75 \\
(0.57-0.95)\end{array}$ & 64534 & $\begin{array}{l}0.75 \\
(0.56-0.94)\end{array}$ & 53511 & $\begin{array}{l}0.59 \\
(0.43-0.78)\end{array}$ & 11384 & $\begin{array}{l}0.59 \\
(0.42-0.772)\end{array}$ & 4366 \\
\hline
\end{tabular}

Data are presented as median and lower upper quartile or as percentage and represent the first year available per patient.

SA, sensitivity analysis.

$(7.98-8.04) \%)$ in the year 2018. For girls, an even more pronounced decrease from $67.17(66.59-67.76) \mathrm{mmol} /$ mol $(8.30(8.24-8.35) \%)$ to $64.70(64.36-65.04) \mathrm{mmol} /$ mol (8.07 (8.04-8.10) \%) was seen, almost closing the earlier HbA1c gap between boys and girls (figure 1A). The SA confirmed this trend (see online supplemental figure S1A). Categorizing the youth population in individuals with and without migrant background revealed that the group without migrant background underwent a convergence tour between boys and girls' HbAlc values (figure $1 \mathrm{~B}$ ), passing the significance level in the SA $(p=0.039$ for the interaction of year and sex, online supplemental figure $\mathrm{S} 1 \mathrm{~B}$ ). The youth group with a migrant background showed a persistent distance between boys and girls' HbAlc values, although also with a trend toward convergence (figure $1 \mathrm{C}$, verified by SA (online
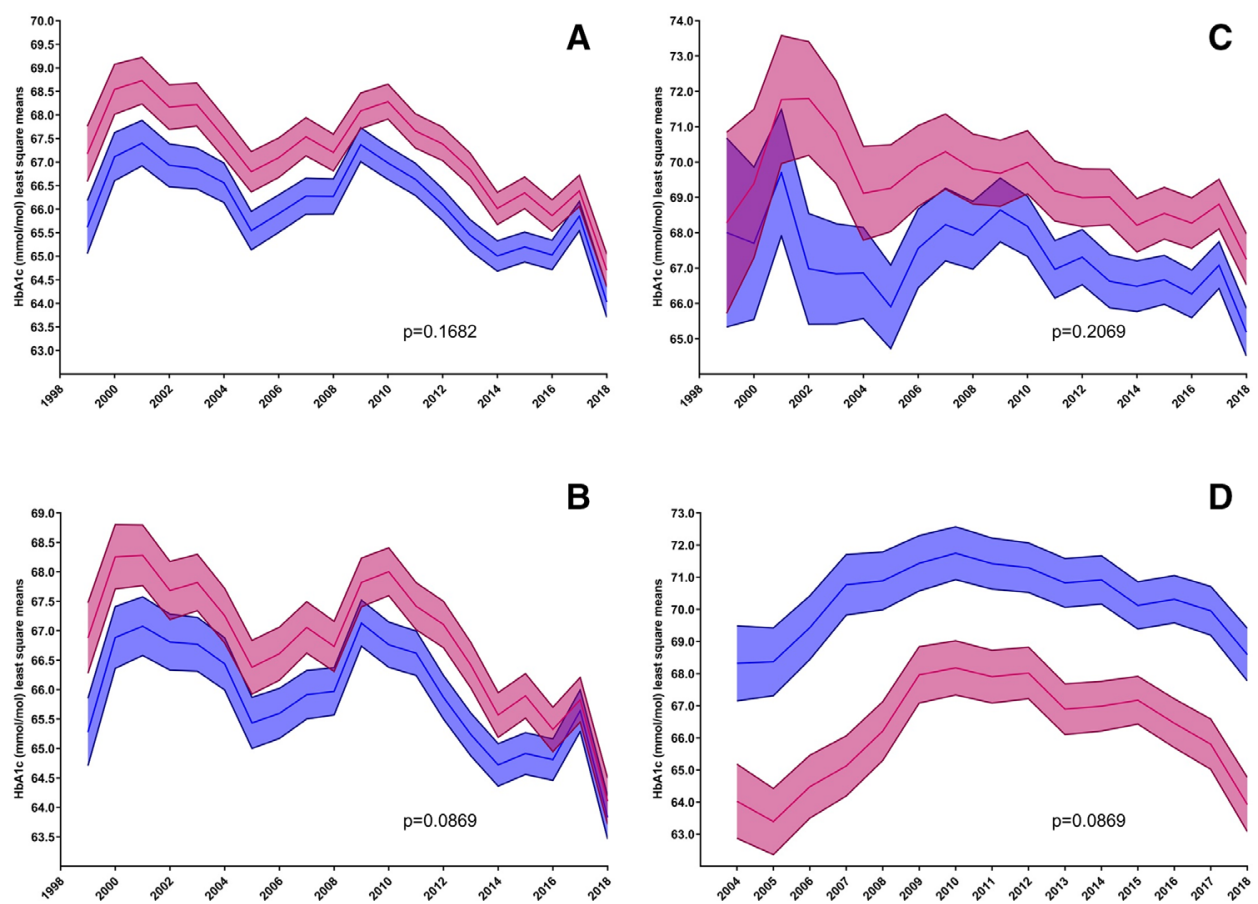

Figure 1 Least square means and $95 \% \mathrm{Cl}$ for $\mathrm{HbA} 1 \mathrm{c}(\%)$ over time for the whole youth group (A), for youth patients without (B) and with a migrant background (C) and adult group (D). Purple: females. Blue: males. 
supplemental figure S1C)). Comparing girls with migrant background to girls without a migrant background and boys with migrant background to boys without migrant background showed a difference in HbAlc values, especially in boys $(\mathrm{p}=0.0037)$ (girls: $\mathrm{p}=0.0748)$, verified by SA (boys: $p=0.0025$; girls: $p=0.1415$ ). A pronounced decline in HbA1c values occurred among all youth groups 20162018 for girls and boys.

Adult male patients started with an HbAlc of 68.32 $(67.15-69.49) \mathrm{mmol} / \mathrm{mol}(8.40(8.29-8.51) \%)$ in 2004 , peaked in 2010 with $71.75(70.93-72.57) \mathrm{mmol} / \mathrm{mol}(8.72$ $(8.64-8.79) \%)$ and decreased until 2018 to 68.59 (67.77$69.41) \mathrm{mmol} / \mathrm{mol}(8.43(8.35-8.50) \%)$. The females paralleled this trend curve while displaying a constantly lower HbA1c (figure 1D). The SA, however, showed a (temporary) convergence of females and males' HbAlc values starting in 2009 and a divergence in 2018, leaving the males with an HbAlc of $63.14(62.29-63.98) \mathrm{mmol} /$ mol $(7.93(7.85-8.00) \%)$ and the females with an HbAlc of $61.27(60.40-62.14) \mathrm{mmol} / \mathrm{mol}(7.76(7.68-7.84) \%)$ $(\mathrm{p}=0.0039) \quad$ (online supplemental figure S1D).

\section{Insulin pump use}

The use of insulin pumps underwent a steep and continuous increase from 1999 to 2018 in the youth group, favoring girls cumulatively over the years: approximately $2.6 \%$ of boys and girls used this technique in 1999. In 2018 , the percentage of boys using insulin pumps was $45 \%$, and in girls 53\% (figure 2A). The SA showed a similar trend (online supplemental figure S2A). Stratifying the youth group by migrant background, the pattern remains similar for individuals with and without a migrant background. However, the percentage of girls and boys with a migrant background who received an insulin pump therapy was lower (girls $48 \%$, boys $39 \%$ in 2018) than girls and boys without a migrant background (girls 54\%, boys $47 \%$ in 2018). In the adult group, considerably more females than males used insulin pumps. Females started in 2004 with 28\% pump use, males with $18 \%$; in 2018, 49\% (females) and 30\% (males) used insulin pumps (figure 2B). The SA verified the findings (online supplemental figure S2B).

\section{Insulin dose trends and BMI-SDS trends}

The daily insulin dose in units per kilogram body weight per day in the youth group increased steeply from 1999 to 2005 and was divergent for boys and girls: In 1999, boys had a documented insulin dose of $0.77(0.76-$ $0.78) \mathrm{IU} / \mathrm{kg} /$ day, girls of $0.82(0.81-0.83) \mathrm{IU} / \mathrm{kg} /$ day. From 2006 onwards, the differences almost vanished, ending up in 2018-after a continuous increase-at a daily dose of $0.90(0.90-0.91) \mathrm{IU} / \mathrm{kg} /$ day in boys and $0.90(0.89-0.90) \mathrm{IU} / \mathrm{kg} /$ day in girls $(\mathrm{p}<0.001$ for the interaction of year and sex) (figure $3 \mathrm{~A}$ ). The SA reinforced this result (online supplemental figure S3A). A similar trend curve showing a convergence of insulin doses for boys and girls over time with an even earlier
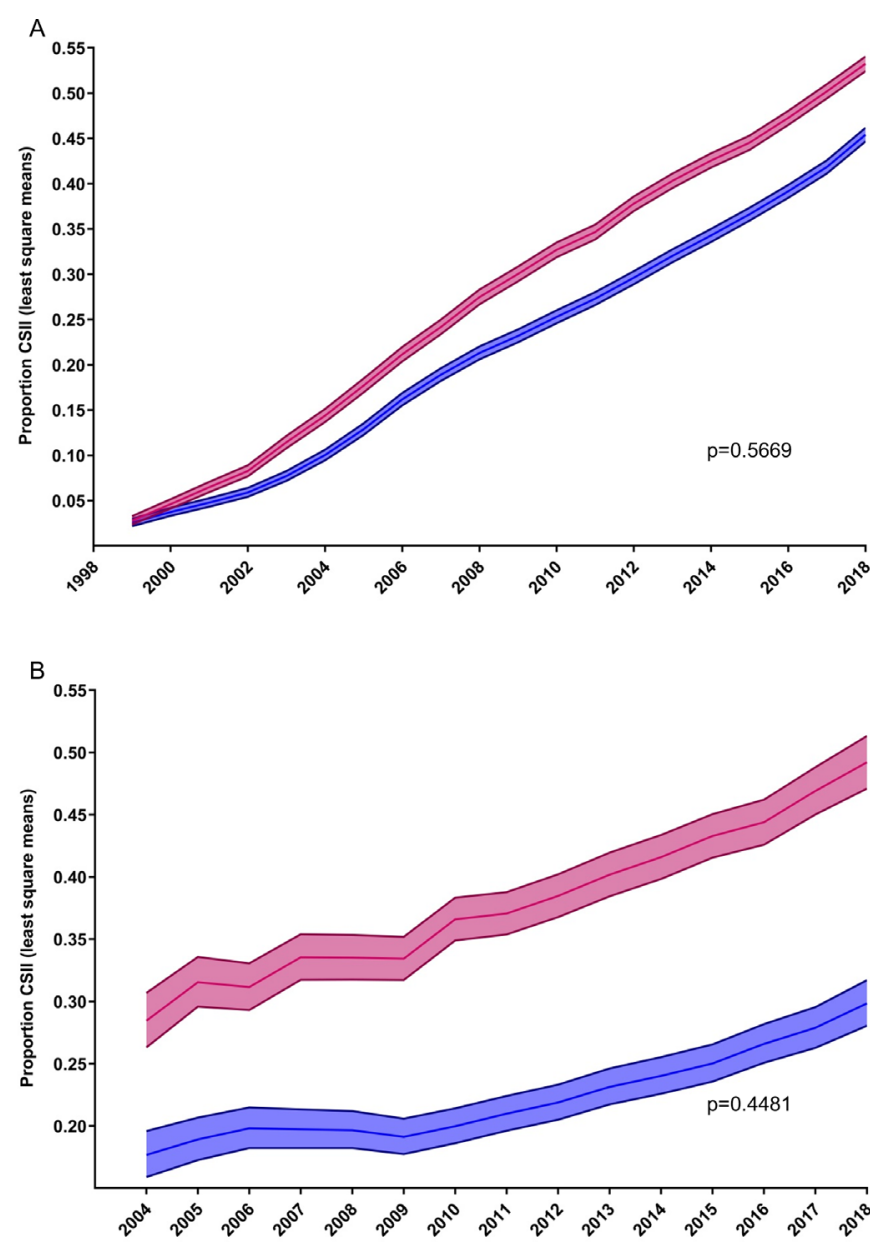

Figure 2 Least square means and $95 \% \mathrm{Cl}$ for proportion continuous subcutaneous insulin infusion (CSII) over time for youth group (A) and adult group (B). Purple: females. Blue: males.

beginning could be seen for those individuals without a migrant background (figure 3B), but not for individuals with a migrant background. With a migrant background, the gap between boys and girls closed as late as from 2015 onwards (figure 3C). For the adult group, the trend course shows fewer fluctuations: In 2004, there was no difference in the daily insulin dose in units per kilogram body weight in males $(0.67(0.65-0.69) \mathrm{IU} /$ $\mathrm{kg} /$ day) and females (0.67 (0.65-0.69) IU/kg/day) . After peaking in males in 2009 (0.73 (0.71-0.74) IU/ $\mathrm{kg} /$ day), the insulin dose was $0.71(0.69-0.72) \mathrm{IU} / \mathrm{kg} /$ day in males and $0.69(0.68-0.71) \mathrm{IU} / \mathrm{kg} /$ day in females in 2018 (figure 3D).

The BMI-SDS constantly rose in the youth group girls over the observed period: in 1999, the girls' BMI-SDS was 0.33 (0.31-0.35), in 20180.63 (0.62-0.64) (figure 4A). Whether without a migrant background or with a migrant background, the gain in BMI-SDS was consistently higher in girls than in boys (figure 4B,C). In adults, males showed persistently lower BMI-SDS values than females (figure 4D). Online supplemental figure S4A-D shows the respective SA results. 

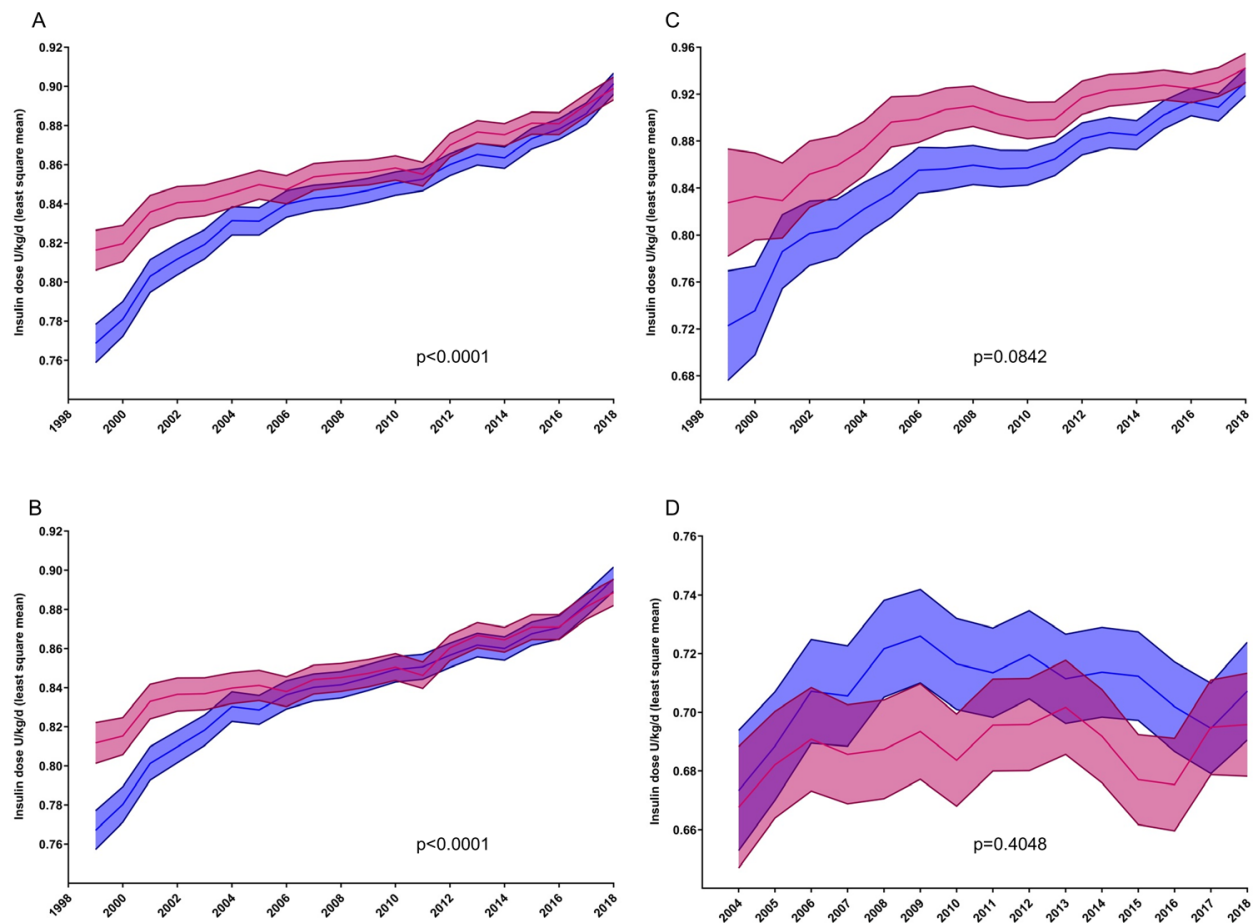

Figure 3 Least square means and $95 \% \mathrm{Cl}$ for insulin dose $/ \mathrm{kg} /$ day over time for the whole youth group (A), for youth patients without $(B)$, with a migrant background $(C)$ and adults $(D)$. Purple lines: females. Blue lines: males.

\section{CONCLUSION}

Our study about sex differences in glycemic control, pump use and insulin dose demonstrates many dynamic changes over time. One of the most important findings is that the boys and girls' (youth group) glycemic control, represented by $\mathrm{HbA1c}$, drew nearer over the last 3years-although this holds for patients without a

A
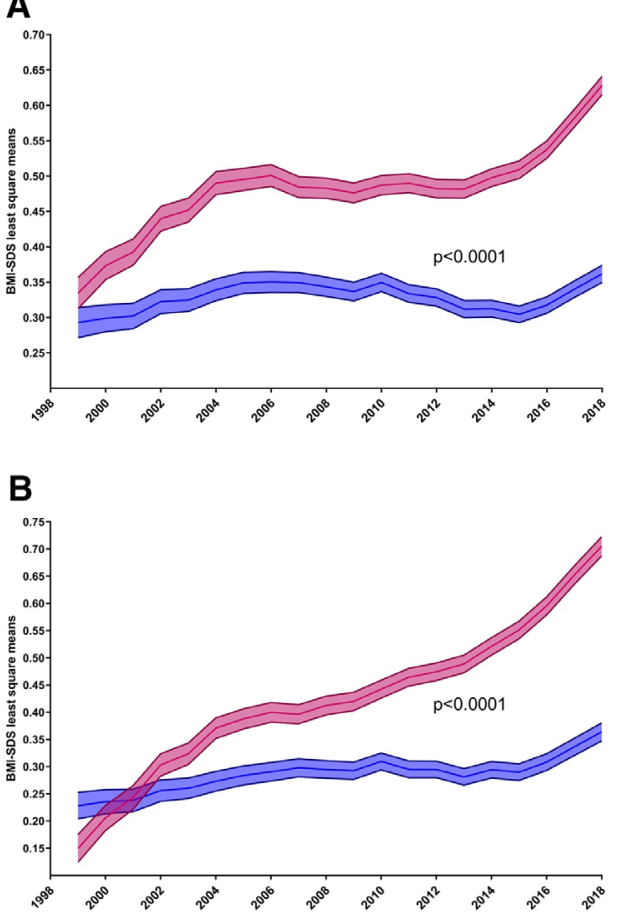

migrant background mainly—settling on a lower level than 20 years ago for both sexes. Over decades, studies reported the girls' metabolic control to be poorer than the boys' ${ }^{15-17}$ The boys and girls' intrinsic physiology has not changed, so the root must lie in something extrinsic and behavioral. As the proportion of girls using pumps increased almost 20-fold from 1999 to 2018, but only

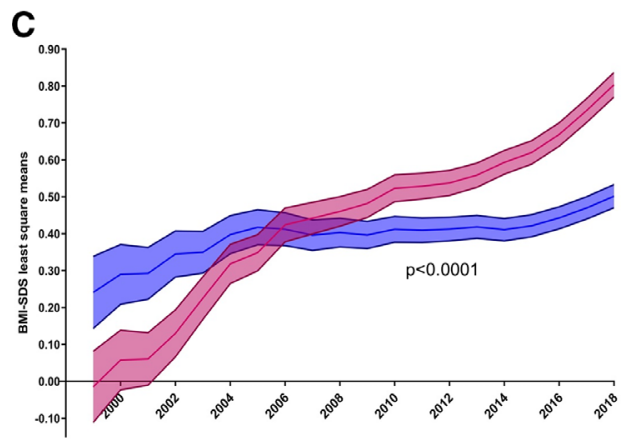

D

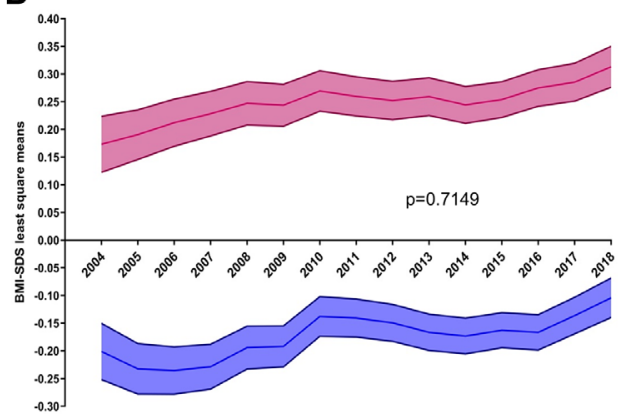

Figure 4 Least square means and 95\% Cl for body mass index SD scores (BMI-SDS) over time for the whole youth group (A), for youth patients without (B), with a migrant background (C) and adults (D). Purple lines: females. Blue lines: males. 
18-fold in boys, this could be a partial explanation. Extensive cohort studies ${ }^{18-20}$ and review papers ${ }^{21}$ provided evidence for improved clinical outcomes by insulin pump use, especially in children, but also showed that boys were treated less often with a pump compared with girls. ${ }^{18} 22$ A reason for treating more girls than boys with insulin pumps over the years might have been the long-standing worse glycemic control in girls, ${ }^{15-17} 23$ as unsatisfying glycemic control is one of the primary and recognized indications for treatment with insulin pumps. Girls might even display more acceptance for insulin pumps than boys. Another explanation for the vanishing HbAlc sex difference is an altered daily insulin dose: earlier studies have shown that both daily insulin dosage and HbAlc were significantly higher in female children and adolescents. ${ }^{24}$ However, we could demonstrate in this study that both girls and boys used continuously increasing insulin doses since 1999, leading to diminished and, in the end, non-existent insulin dose differences between girls and boys. The general insulin dose increase might be due to the attempt to achieve the international and national guidelines' HbAlc targets $(53 \mathrm{mmol} / \mathrm{mol}(<7 \%))$ via tighter glucose control, accompanied by increasing use of technical devices (flash/continuous glucose monitoring (CGM)) guaranteeing avoidance of hypoglycemic events particularly. ${ }^{9}$ The increasing BMI-SDS might also contribute to the increased insulin dose indicating insulin resistance. However, the girls showed a steep increase in BMI-SDS but a less steep increase in insulin doses than boys. The girls' less steep increase might result from their higher insulin pump use: we know that this technique requires less insulin than multiple daily injections. ${ }^{19} 20$ However, care should be taken not to overinterpret the longitudinal insulin dosage data: early study data originate from patients' statements linked with the possibility of under-reporting of meals and their corresponding insulin dosages. Data from recent years, partly from the reliable insulin pump and technical device readings, are probably closer to the accurate insulin dosage.

More factors contribute to the changes in glycemic control and the boys and girls' HbAlc convergence in the youth group. Greater self-control that is attributed to girls' behavior compared with boys', resulting, for example, in better grades, ${ }^{25}$ is a trait that may lead to better or excellent glycemic control. However, these girls' characteristic is hardly something new for the last couple of years. More likely, a change in treatment and social interaction, particularly in girls and adolescent females, took place, perhaps partly due to the introduction of gender medicine in medical school, ${ }^{5}$ partly due to generally changing gender stereotypes as stated in a meta-analysis by Eagly et $a l^{26}$ and partly maybe due to the increased number of female physicians. The female physician factor was associated with a higher quality of care in an Irish review and meta-analysis about the quality of diabetes management in primary care. ${ }^{27}$ Besides the factors mentioned above, we must not forget the tighter HbAlc targets that were molded into International Society for Pediatric and Adolescent Diabetes (ISPAD)'s guidelines in 2018 but were anchored in diabetologists' minds long beforehand: The clinicians' treatment target for their patients matter in the management of children and adolescents with type 1 diabetes, as shown in a small Australian study by Cameron $e t a l^{28}$ Especially those children and adolescents with inadequate glycemic control - namely girls - would have come to the fore with the lower HbAlc target to get their HbAlc closer to the pursued target.

The general and pronounced HbA1c decline from 2016 to 2018 in all adolescents might be an effect of increased use of CGM: in 2016 the reimbursement by health insurances started and resulted in a tremendous increase of CGM use. ${ }^{29}$ A recent study confirmed the benefit of CGM in adolescents and young adults with regard to glycemic control. ${ }^{30}$ Additional factors like newer drugs, for example, glucagon like peptide 1 (GLP1) receptor agonist, are unlikely to have contributed to the HbAlc decline, as they had no approval for children and adolescents in the mentioned period.

Unfortunately, the general and the girls' glycemic control improvement has not yet reached the same level in those children and adolescents with a migrant background, although a convergence trend can be observed. Moreover, the use of insulin pumps turned out to be somewhat lower than in those patients without a migrant background, although increasing over time and showing the same pattern with more girls than boys using pumps. There seems to be a time lag in improvements for people with type 1 diabetes and migrant background. For years, we have known that minorities with type 1 diabetes are disadvantaged in health systems. ${ }^{31-34}$ We have not yet found an optimal way of communicating with children and adolescents with a migrant background and their families. Similar to the implementation of gender medicine since the 1990s, there are attempts to create an enabling environment for migration and health research at national, regional and global levels. ${ }^{35}$ An active part for diabetologists in this process will hopefully lead to success over the next decade.

Glycemic control trends for the adult group showed a temporary increase of HbA1c up to 2010 and a decrease until 2018, ending up (SA) with a marginally improved HbA1c compared with 2004. One reason for the downward direction of $\mathrm{HbAlc}$ values might be the pronounced use of CGM since 2016, especially in young adults. ${ }^{29}$ Additional contributing factors could be a change towards new long-acting insulins. Other influencing newer diabetes drugs like sodium dependent glucose co-transporter $1 / 2$ (SGLT1/2) inhibitors can be excluded as they were not approved for type 1 diabetes during the study period.

From 2004 to 2018, females had lower HbAlc and needed lower daily insulin doses per kilogram body weight, despite constantly higher BMI-SDS and potentially negatively influencing factors like menstrual cycles, luteal phase changes in insulin sensitivity or use of hormonal contraception. ${ }^{36}$ This glycemic control observation contrasts with other European or US studies: from 2004 to 2016, Scottish women with type 1 diabetes had consistently slightly higher average HbAlc than 
men. ${ }^{37}$ The same pattern was seen in young Italian adults aged 18-30 years with type 1 diabetes. ${ }^{38}$ Data from the T1D Exchange Registry showed similar HbAlc results in women and men with type 1 diabetes. ${ }^{39}$ One possible explanation for this sex difference in the DPV cohort might be that more women than men use insulin pumps-undoubtedly due to the recommendation to use insulin pumps during pregnancy and preconceptionally. The Scottish registry and the T1D Exchange study mentioned above report the same gender distribution for insulin pump use. However, they show no or even reversed HbAlc sex differences. The known sex differences in energy balance and metabolic homeostasis (inter alia higher skeletal muscle mass, higher visceral adiposity, and higher glucose oxidation in men, higher total fat mass, higher subcutaneous adiposity, and higher insulin sensitivity in woman) that influence glycemic control (reviewed in ref 40) are expected to be similar within the human species worldwide, and therefore cannot explain these contradictive findings. That leaves us with environmental factors that theoretically might play a role. A European study using data from the Survey of Health, Aging and Retirement showed that sex differences in cognitive functions vary systematically across birth cohorts and regions. The authors stated that improved living conditions and less gender-restricted educational opportunities are associated with increased gender differences favoring women in cognitive functions and decreasing or eliminating differences in other cognitive abilities. ${ }^{41}$ Nevertheless, whether this changing face of cognitive gender differences is actually associated with the sex differences seen in our DPV cohort remains more than speculative and has to be entrusted for further studies. It also remains speculative whether factors, such as, for example, socioeconomic status or the time spent at home or at work, influence glycemic control and explain sex differences. These data are not systematically recorded in DPV.

Our study has a few more limitations: the adult DPV cohort is the 'younger' group in the DPV, as DPV started initially in 1995 as a pediatric diabetes registry. While the sizeable pediatric cohort is now population based and represents approximately $90 \%$ of the children with type 1 diabetes in Germany, the adult cohort—although growing-is still clinic based. Hence, the period of the adult group in our study is shorter than the youth group's period. Moreover, the SA reduces the initial cohort by a factor of 2.3 from $n=15380$ to $n=6672$ participants. Despite still comprising a large number of adult patients, this is a limitation of our study. Another limitation is the incomplete documentation of migrant background in the adult group: in Germany alone, about $26 \%$ of the population had a migrant background in $2019 ;{ }^{42}$ thus, the documented proportion of $1.5 \%$ in the study population is highly underestimated. We have to assume that many adults with a migrant background have been included in the non-migration subgroup. Stratification by migrant background was therefore not carried out.

In summary, we identified a closing gap concerning sex differences regarding improved glycemic control over time in a population of children and adolescents with type 1 diabetes without a migrant background. Sex differences seem to persist longer in patients with a migrant background, showing a time lag. Improvements in glycemic control are accompanied by increased insulin pump use, favoring girls, and an increased daily insulin dose, favoring boys. In the adult population, women persistently show better glycemic control and use insulin pumps more often than men. The discussed explanations for the observed sex differences remain speculative.

\section{Author affiliations}

${ }^{1}$ Paediatric Endocrinology and Diabetology, University of Bern Faculty of Medicine, Bern, Switzerland

${ }^{2}$ Institute of Epidemiology and Medical Biometry (ZIBMT), University of UIm, Ulm, Germany

${ }^{3}$ German Centre for Diabetes Research (DZD), Munich-Neuherberg, Germany ${ }^{4}$ Department of General Paediatrics, Neonatology and Paediatric Cardiology, Medical Faculty, University Children's Hospital, Düsseldorf, Germany

${ }^{5}$ Paediatric Endocrinology and Diabetology, University of Bonn, Bonn, Germany ${ }^{6}$ Sylt Specialist Clinic for Children and Adolescents, Westerland, Germany

${ }^{7}$ Department of Paediatrics, University Hospital Jena, Jena, Germany

${ }^{8}$ Clinic for Internal Medicine-Diabetology and Angiology Mitte, DRK Hospitals Berlin, Berlin, Germany

${ }^{9}$ Diabetes Centre Forchheim, Forchheim, Germany

Acknowledgements Tremendous thanks go to RW Holl (Institute of Epidemiology and Medical Biometry (ZIBMT), Ulm University; German Centre for Diabetes Research (DZD)), the inventor and initiator of DPV. Special thanks to A Hungele (ZIBMT), Ulm University; DZD, and R Ranz (ZIBMT), Ulm University; DZD, for support and the development of the DPV documentation software, and K Fink (ZIBMT), Ulm University; DZD, and E Bollow (ZIBMT), Ulm University; DZD, for the DPV data management (all clinical data managers).

Contributors CB, SRT, TM and SL conceived and designed the analysis. CB wrote/ drafted the paper. SRT and SL contributed data and analysis tools and performed the analysis. CB, TM, BG, RS, AD, SW, and IL collected the data. SRT, TM, BG, RS, $A D, S W, I L$ and SL critically revised the article for its intellectual content. All authors approved the final version of the manuscript. $\mathrm{CB}$ acts as guarantor for the work

Funding Financial support was provided by the German Centre for Diabetes Research (DZD, grant number 82DZD14A02) and by the Robert Koch Institute (RKI, grant number 1368-1711).

Disclaimer The study funder was not involved in the design of the study; the collection, analysis, and interpretation of data; writing the report; and did not impose any restrictions regarding the publication of the report.

Competing interests None declared.

Patient consent for publication Not required.

Ethics approval This study involves human participants and was approved by the Institutional Review Board of the University of Ulm (reference number 202/09). Participants gave informed consent to participate in the study before taking part. The DPV initiative obtained ethics approval from the Ethics Committee of the University of Ulm.

Provenance and peer review Not commissioned; externally peer reviewed.

Data availability statement Data are available upon reasonable request. Data are available upon request via the corresponding author.

Supplemental material This content has been supplied by the author(s). It has not been vetted by BMJ Publishing Group Limited (BMJ) and may not have been peer-reviewed. Any opinions or recommendations discussed are solely those of the author(s) and are not endorsed by BMJ. BMJ disclaims all liability and responsibility arising from any reliance placed on the content. Where the content includes any translated material, BMJ does not warrant the accuracy and reliability of the translations (including but not limited to local regulations, clinical guidelines, terminology, drug names and drug dosages), and is not responsible for any error and/or omissions arising from translation and adaptation or otherwise.

Open access This is an open access article distributed in accordance with the Creative Commons Attribution Non Commercial (CC BY-NC 4.0) license, which 
permits others to distribute, remix, adapt, build upon this work non-commercially, and license their derivative works on different terms, provided the original work is properly cited, appropriate credit is given, any changes made indicated, and the use is non-commercial. See: http://creativecommons.org/licenses/by-nc/4.0/.

ORCID iD

Claudia Boettcher http://orcid.org/0000-0001-5494-2616

\section{REFERENCES}

1 Mauvais-Jarvis F, Bairey Merz N, Barnes PJ, et al. Sex and gender: modifiers of health, disease, and medicine. Lancet 2020;396:565-82.

2 Huxley RR, Peters SAE, Mishra GD, et al. Risk of all-cause mortality and vascular events in women versus men with type 1 diabetes: a systematic review and meta-analysis. Lancet Diabetes Endocrinol 2015;3:198-206.

3 Borschuk AP, Everhart RS. Health disparities among youth with type 1 diabetes: a systematic review of the current literature. Fam Syst Health 2015;33:297-313.

4 Manderson L. Teaching gender, teaching women's health: introduction. Women Health 2003;37:1-9.

5 Hochleitner M, Nachtschatt U, Siller H. How do we get gender medicine into medical education? Health Care Women Int 2013;34:3-13.

6 Legato MJ, Johnson PA, Manson JE. Consideration of sex differences in medicine to improve health care and patient outcomes. JAMA 2016;316:1865-6.

7 Regensteiner JG, Libby AM, Huxley R, et al. Integrating sex and gender considerations in research: educating the scientific workforce. Lancet Diabetes Endocrinol 2019;7:248-50.

8 Krüger-Brand HE. E-Health: den Gender-Bias vermeiden. Dtsch Arzteb/ 2020;117:A-478 / B-416.

9 van den Boom L, Karges B, Auzanneau M, et al. Temporal trends and contemporary use of insulin pump therapy and glucose monitoring among children, adolescents, and adults with type 1 diabetes between 1995 and 2017. Diabetes Care 2019;42:2050-6.

10 DiMeglio LA, Acerini CL, Codner E, et al. ISPAD clinical practice consensus guidelines 2018: glycemic control targets and glucose monitoring for children, adolescents, and young adults with diabetes. Pediatr Diabetes 2018;19 Suppl 27:105-14.

11 American Diabetes Association. 6. Glycemic Targets: Standards of Medical Care in Diabetes-2020. Diabetes Care 2020;43:S66-76.

12 McKnight JA, Wild SH, Lamb MJE, et al. Glycaemic control of Type 1 diabetes in clinical practice early in the 21st century: an international comparison. Diabet Med 2015;32:1036-50.

13 Diabetes Control and Complications Trial Research Group, Nathan DM, Genuth S, et al. The effect of intensive treatment of diabetes on the development and progression of long-term complications in insulin-dependent diabetes mellitus. N Engl J Med 1993;329:977-86.

14 Kromeyer-Hauschild K, Wabitsch M, Kunze D, et al. Perzentile für den Body-mass-Index für das Kindes- und Jugendalter unter Heranziehung verschiedener deutscher Stichproben. Monatsschr Kinderheilkd 2001;149:807-18.

15 Mortensen HB, Robertson KJ, Aanstoot HJ, et al. Insulin management and metabolic control of type 1 diabetes mellitus in childhood and adolescence in 18 countries. Hvidøre Study Group on childhood diabetes. Diabet Med 1998;15:752-9.

16 Gerstl E-M, Rabl W, Rosenbauer J, et al. Metabolic control as reflected by $\mathrm{HbA} 1 \mathrm{c}$ in children, adolescents and young adults with type-1 diabetes mellitus: combined longitudinal analysis including 27,035 patients from 207 centers in Germany and Austria during the last decade. Eur J Pediatr 2008;167:447-53.

17 Samuelsson U, Anderzén J, Gudbjörnsdottir S, et al. Teenage girls with type 1 diabetes have poorer metabolic control than boys and face more complications in early adulthood. J Diabetes Complications 2016;30:917-22.

18 Sherr JL, Hermann JM, Campbell F, et al. Use of insulin pump therapy in children and adolescents with type 1 diabetes and its impact on metabolic control: comparison of results from three large, transatlantic paediatric registries. Diabetologia 2016;59:87-91.

19 Szypowska A, Schwandt A, Svensson J, et al. Insulin pump therapy in children with type 1 diabetes: analysis of data from the sweet registry. Pediatr Diabetes 2016:17 Suppl 23:38-45.

20 Karges B, Schwandt A, Heidtmann B, et al. Association of insulin pump therapy vs insulin injection therapy with severe hypoglycemia, ketoacidosis, and glycemic control among children, adolescents, and young adults with type 1 diabetes. JAMA 2017;318:1358-66.
21 Nimri R, Nir J, Phillip M. Insulin pump therapy. Am J Ther 2020;27:e30-41.

22 Burckhardt M-A, Smith GJ, Cooper MN, et al. Real-World outcomes of insulin pump compared to injection therapy in a populationbased sample of children with type 1 diabetes. Pediatr Diabetes 2018;19:1459-66.

23 Moore JM, Snell-Bergeon JK. Trajectories of hemoglobin A1c and body mass index z-score over four decades among 2 to 18 year olds with type 1 diabetes. Pediatr Diabetes 2019;20:594-603.

24 Knerr I, Hofer SE, Holterhus PM, et al. Prevailing therapeutic regimes and predictive factors for prandial insulin substitution in 26687 children and adolescents with type 1 diabetes in Germany and Austria. Diabet Med 2007;24:1478-81.

25 Duckworth AL, Shulman EP, Mastronarde AJ, et al. Will not want: self-control rather than motivation explains the female advantage in report card grades. Learn Individ Differ 2015;39:13-23.

26 Eagly AH, Nater C, Miller DI, et al. Gender stereotypes have changed: a cross-temporal meta-analysis of U.S. public opinion polls from 1946 to 2018. Am Psychol 2020;75:301-15.

27 Riordan F, McHugh SM, O'Donovan C, et al. The role of physician and practice characteristics in the quality of diabetes management in primary care: systematic review and meta-analysis. J Gen Intern Med 2020;35:1836-48.

28 Cameron FJ, Russell E, McCombe J, et al. The clinician factor: personality characteristics of clinicians and their impact upon clinical outcomes in the management of children and adolescents with type 1 diabetes. Pediatr Diabetes 2018;19:832-9.

29 Miller KM, Hermann J, Foster N, et al. Longitudinal changes in continuous glucose monitoring use among individuals with type 1 diabetes: international comparison in the German and Austrian DPV and U.S. T1D exchange registries. Diabetes Care 2020;43:e1-2.

30 Laffel LM, Kanapka LG, Beck RW. CGM intervention in teens and young adults with T1D (City) Study Group; CDE10. Effect of continuous glucose monitoring on glycemic control in adolescents and young adults with type 1 diabetes: a randomized clinical trial. JAMA 2020:323:2388-96.

31 Icks A, Razum O, Rosenbauer J, et al. Lower frequency of insulin pump treatment in children and adolescents of Turkish background with type 1 diabetes: analysis of 21,497 patients in Germany. Diabetes Technol Ther 2012;14:1105-9.

32 Khanolkar AR, Amin R, Taylor-Robinson D, et al. Young people with type 1 diabetes of non-white ethnicity and lower socio-economic status have poorer glycaemic control in England and Wales. Diabet Med 2016;33:1508-15.

33 Mönkemöller K, Müller-Godeffroy E, Lilienthal E, et al. The association between socio-economic status and diabetes care and outcome in children with diabetes type 1 in Germany: the DIAS study (diabetes and social disparities). Pediatr Diabetes 2019;20:637-44.

34 Chepulis L, Tamatea JAU, Wang C, et al. Glycaemic control across the lifespan in a cohort of new Zealand patients with type 1 diabetes mellitus. Intern Med J 2021:51:725-31.

35 Wickramage K, Vearey J, Zwi AB, et al. Migration and health: a global public health research priority. BMC Public Health 2018;18:987

36 Goldner WS, Kraus VL, Sivitz WI, et al. Cyclic changes in glycemia assessed by continuous glucose monitoring system during multiple complete menstrual cycles in women with type 1 diabetes. Diabetes Technol Ther 2004;6:473-80.

37 Mair C, Wulaningsih W, Jeyam A, et al. Glycaemic control trends in people with type 1 diabetes in Scotland 2004-2016. Diabetologia 2019;62:1375-84.

38 Maiorino MI, Bellastella G, Casciano O, et al. Gender-differences in glycemic control and diabetes related factors in young adults with type 1 diabetes: results from the Metro study. Endocrine 2018;61:240-7.

39 Shah VN, Wu M, Polsky S, et al. Gender differences in diabetes selfcare in adults with type 1 diabetes: findings from the T1D exchange clinic registry. J Diabetes Complications 2018;32:961-5.

40 Tramunt B, Smati S, Grandgeorge N, et al. Sex differences in metabolic regulation and diabetes susceptibility. Diabetologia 2020;63:453-61.

41 Weber D, Skirbekk V, Freund I, et al. The changing face of cognitive gender differences in Europe. Proc Natl Acad Sci U S A 2014;111:11673-8.

42 D_Statis (Statistisches Bundesamt). Available: https://www.destatis. de/DE/Themen/Gesellschaft-Umwelt/Bevoelkerung/MigrationIntegration/_inhalt.html [Accessed Jun 2021]. 